\section{Encefalopatía tóxica por isopropanol. Sobre-exposición accidental a gas propano}

\author{
LUIS CARTIER R., ANDRÉS GALLARDO V.
}

\section{Toxic encephalopathy caused by liquefied gas exposure. Report of one case}

Liquefied hydrocarbon gas, such as propane is considered safe. However there are reports that voluntary exposure to liquefied gas at least could originate hallucinatory states. We report a 20 years old woman who was found in a coma with extensor muscle hypertonia, brisk tendon reflexes and extensor plantar (Babinski) responses after being exposed to propane gas. The brain magnetic resonance imaging (MRI) showed lesions in both hippocampi and white matter in the oval center. The patient had a normal oxygen saturation of $98 \%, a$ carboxyhemoglobin of $1.6 \%$ and a metabolic acidosis with a $\mathrm{pH}$ of 7.01 with an anion gap of $16 \mathrm{mEq} / \mathrm{l}$. This pattern suggested that it was a consequence of the intermediary metabolism of isopropanol. The recovery of the patient was slow and four months later she still had lesions on MRI and limitations in her cognitive sphere, memory and executive functions. Thus, liquefied gas exposure can cause a toxic encephalopathy with a persistent damage of the central nervous system.

(Rev Med Chile 2016; 144: 1083-1087)

Key words: Gas Poisoning; Neurotoxicity Syndromes; Propanol.
Departamento de Ciencias Neurológicas Oriente, Facultad de Medicina, Universidad de Chile. Servicio de Neurología, Hospital del Salvador. Santiago, Chile.

Recibido el 25 de agosto de 2015, aceptado el 21 abril de 2016.

Correspondencia a:

Dr. Luis Cartier R.

Departamento de Ciencias Neurológicas Oriente Facultad de Medicina Universidad de Chile. Icartier@med.uchile.cl $\longrightarrow$ on cierta frecuencia se han comunicado personas que desarrollaron estados de conciencia alterada, después de exposiciones accidentales o voluntarias a gas licuado de petróleo (GLP), donde no se pudo comprobar hipoxia o intoxicación con monóxido de carbono como causa subyacente. Estas comunicaciones han permitido establecer que el propano, principal componente del GLP, puede producir efectos deletéreos sobre el sistema nervioso central (SNC) traducidos en alteración de la vigilancia, estados alucinatorios y eventuales daños estructurales cuyos mecanismos patogénicos no están aún completamente dilucidados ${ }^{1,2}$.

El gas licuado de petróleo es una mezcla comprimida de hidrocarburos alifáticos de cadena corta que en Chile está compuesto por $70 \%$ de propano, 30\% de butano y cantidades menores de otros hidrocarburos. Experimentalmente en concentraciones de 1.000 ppm el propano es incapaz de producir asfixia por bloqueo en el consumo de oxígeno ${ }^{3}$.

En cambio, su alta lipofília permite que la aspiración de GLP impregne con rapidez tejidos con contenido graso, alcanzando elevadas concentraciones en hígado, cerebro, tejido subcutáneo y corazón ${ }^{4}$. Se le ha imputado la génesis de hepatopatías, encefalopatías y arritmias ${ }^{5}$ además de su reconocida capacidad para generar estados alucinatorios que explica su uso como estupefaciente en cárceles de Estados Unidos de Norteamérica ${ }^{6}$.

Estos hidrocarburos de cadena corta son automáticamente metabolizados por el hígado, haciendo que la vida media del gas en el organismo no supere la hora, encontrándose posteriormente sólo residuos alcohólicos y cetónicos del gas ${ }^{7,8}$. El isopropanol y el butanol son alguno de los metabolitos identificados, alcoholes que tienen especial afinidad por el hipocampo y el bulbo olfatorio'.

El isopropanol es un alcohol que tiene di- 
versos usos industriales y es reconocidamente neurotóxico ${ }^{10,12}$. Se han comunicado casos de intoxicación por la ingesta de isopropanol ${ }^{11,12}$, donde destacan pacientes que llegaron al coma y presentaron compromiso de la vía motora central, expresado en hiperreflexia y signo de Babinski. La RM mostró hipointensidad de la substancia blanca en T1 e hiperintensidad en T2 que en algún caso comprometió corteza cerebelosa, regiones temporo-mesiales, ganglios basales y tronco encefálico ${ }^{13}$. Estos sujetos después de haber superado el estado tóxico recuperaron su capacidad funcional, aunque mantuvieron un déficit cognitivo de expresión frontal y subcortical ${ }^{14}$.

Esta comunicación describe una joven paciente sobreexpuesta a gas licuado que desarrolló en lo clínico y neuroimagenológico las características de una intoxicación por isopropanol. Esto hace surgir la necesidad de identificar este tipo de intoxicaciones para evitar confundirlas con hipoxia o intoxicaciones por monóxido de carbono, que son los diagnósticos que surgen en pacientes intoxicados por GLP.

\section{Caso clínico}

Se presenta el caso de una paciente de sexo femenino de 20 años, que fue encontrada inconsciente en la tina de baño. Evaluada localmente por el servicio de urgencia (SAMU) la describen en Glasgow 5, con hipotermia $\left(34,5^{\circ}\right)$, taquicárdica (119/min), sin alteraciones electrocardiográficas y presión arterial normal. Mantenía una saturación de oxígeno de 98\%, sin embargo, estaba polipnei- ca. Ingresó en coma no reactivo al Hospital del Salvador en midriasis y pupilas reactivas a la luz, con hipertonía extensora de las extremidades (en descerebración), hiperreflexia generalizada y signo de Babinski, con crisis extensoras de breve duración. Exámenes: leucocitosis de $36.400 / \mathrm{mm}^{3}$, PCR 0,4 $\mathrm{mg} / \mathrm{dl}, \mathrm{pH} 7,01$, bicarbonato de $15,9 \mathrm{mmol} / \mathrm{l}, \mathrm{EB}$ $-15,7 \mathrm{mmol} / \mathrm{l}$. Anión gap aumentado a $16 \mathrm{mmEq} / \mathrm{l}$, monóxido de carbono (HbCO) 1,6\%, INR 1,32, protrombina de $67 \%$. El examen toxicológico de la orina fue negativo. Líquido cefalorraquídeo (LCR) incoloro, glucosa 0, $50 \mathrm{~g} / \mathrm{l}$, albúmina 34,4 $\mathrm{mg} / \mathrm{dl}, 3$ cels $/ \mathrm{mm}^{3}$, Gram sin bacterias, PCR para herpes zoster (VHS 1 y 2) negativo. La tomografía axial computarizada (TAC) de cerebro al ingreso mostraba cambios en la densidad de los hipocampos (Figura 1a), estos cambios se acentuaron en la TAC del día siguiente, que definió una significativa hipodensidad hipocampal (Figura 1b).

Al cuarto día comenzó a mostrar esporádica apertura ocular con isocoria reactiva, reflejos oculocefálicos y corneanos conservados. Al estímulo mostraba reactividad en las extremidades derechas, manteniendo la hiperreflexia generalizada y Babinski. Electroencefalograma mostró actividad lenta generalizada a $3 \mathrm{cps}$, y alto voltaje $30 \mathrm{mmV}$.

Al séptimo día apareció mirada de seguimiento y aunque no emitía lenguaje, cumplía órdenes. La RNM mostró hiperintensidad y tumefacción de ambos hipocampos en toda su extensión con restricciones en la difusión, sin impregnaciones patológicas tras la administración de contraste. También imágenes hiperintensas en T2 y FLAIR de la substancia blanca del centro semioval y de áreas subcorticales en ambas regiones tempo-

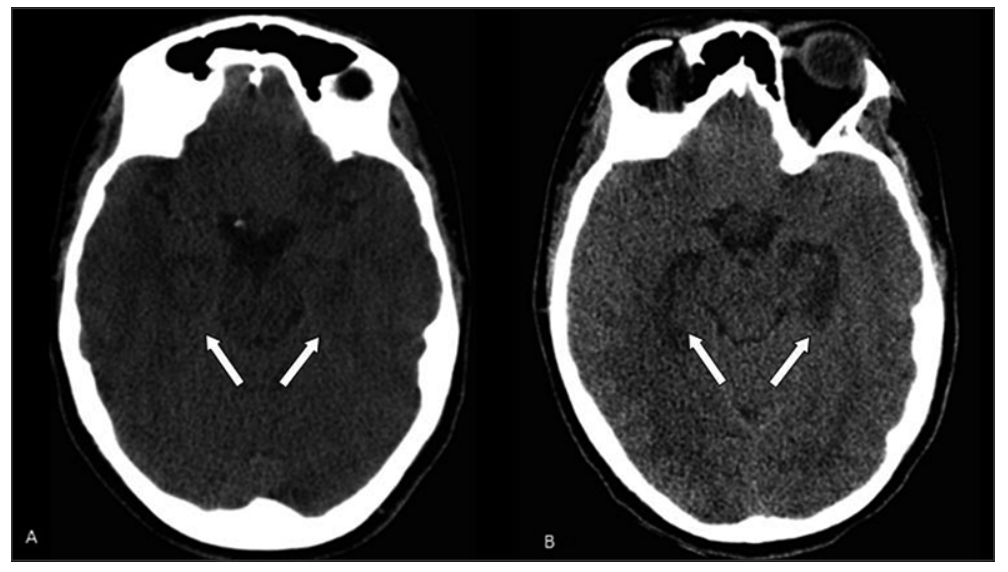

Figura 1. TC de cerebro sin contraste: A) Al ingreso en el Hospital del Salvador: Leve hipodensidad hipocampal bilateral; B) al día siguiente del ingreso: Hipodensidad de ambos hipocampos y disminución de la densidad en la sustancia blanca subcortical más notable en el lado derecho. 


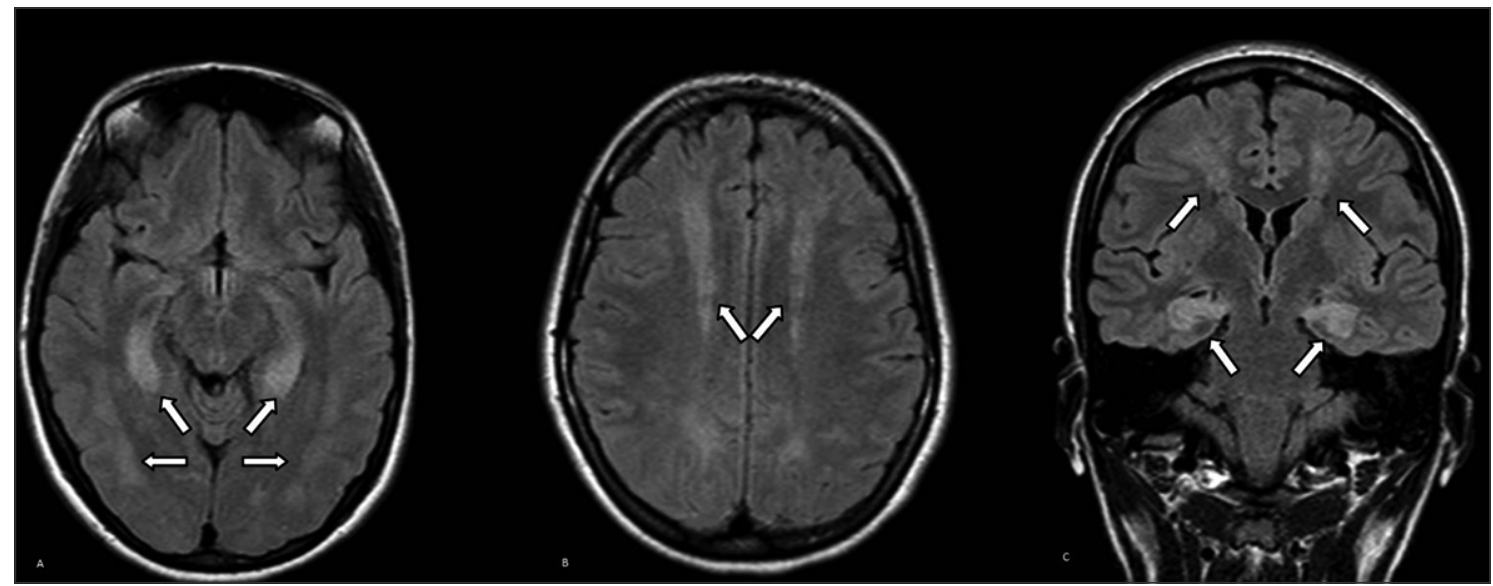

Figura 2. RM de cerebro obtenida al séptimo día A) corte axial, FLAIR: Hiperintensidad de ambos hipocampos y de la sustancia blanca subcortical témporo-occipital, respeto de las fibras U; B) corte axial, FLAIR: Hiperintensidad simétrica de la substancia blanca, en centro semioval; C) corte coronal, FLAIR: Hiperintensidad hipocampal bilateral y de la sustancia blanca frontal.

ro-occipitales, que no mostraban restricciones en la difusión. Hiperintensidad simétrica de la corteza cerebelosa (Figuras $2 \mathrm{a}, \mathrm{b}, \mathrm{c}$ ).

Desde el día decimocuarto presentó períodos más prolongados de vigilia y movía las extremidades derechas de manera rítmica e iterativa, sin propósito aparente, las izquierdas las movía sólo ocasionalmente, lado en que persistía el Babinski. En el día decimosexto se le realizo traqueostomía protectora.

Después del día vigesimo primero se estabilizó el ritmo vigilia-sueño, estaba despierta durante el día, aunque pasiva sin ser capaz de comunicarse. La RM de control mostró mayor hiperseñal en los hipocampos y disminución de la tumefacción de dichas estructuras, persistían la hiperintensidad de la substancia blanca subcortical y del centro oval.

En las semanas que siguieron se produjo una significativa recuperación, logrando ponerse de pie y caminar. Se decanuló de la traqueostomía y pudo emitir lenguaje hipofónico en pocos días. Al trigésimo octavo día había recuperado el lenguaje expresivo y la marcha, sin embargo, seguía pasiva, incapaz de una comunicación espontánea.

Al trigésimo noveno día se realizó una evaluación neuropsicológica formal que encontró desorientación y distractibilidad fácil con fallas atencionales, compromiso de la memoria episódica (retrógrada y anterógrada) y déficits en la capacidad de almacenamiento y evocación. También mostró alteraciones de las funciones ejecutivas con defectos de abstracción y programación, así como pérdida del control inhibitorio.

Fue dada de alta el día cuarenta y controlada un mes después se comprobó marcha normal y lenguaje conservado, aun manteniendo hiperreflexia en extremidades inferiores. Los reflejos plantares eran flexores, se apreció una mínima paresia braquial izquierda asociada a disestesia de los dedos índice y pulgar de esa mano. La RM de control (Figuras 3 a, b, c) mostró áreas quísticas en el centro oval en aquellos sectores de substancia blanca previamente afectados, con atrofia de ambos hipocampos y del bulbo olfatorio. Mantenía el déficit cognitivo.

\section{Comentario}

Hemos presentado el caso de una paciente previamente sana, encontrada inconsciente hora y media después de iniciada una ducha caliente, en una sala de baño con calefón interior abastecido por gas licuado. El equipo de rescate pudo establecer desde el primer momento que la saturación de oxígeno y la presión arterial de la paciente eran normales, pero además le encontraron en hipotermia e hiperventilación acidótica. Inicialmente el diagnóstico diferencial fue difícil, por carecer de elementos que permitieran acercarnos a él. Sin embargo, la acidosis metabólica fue la clave de la orientación etiológica. 


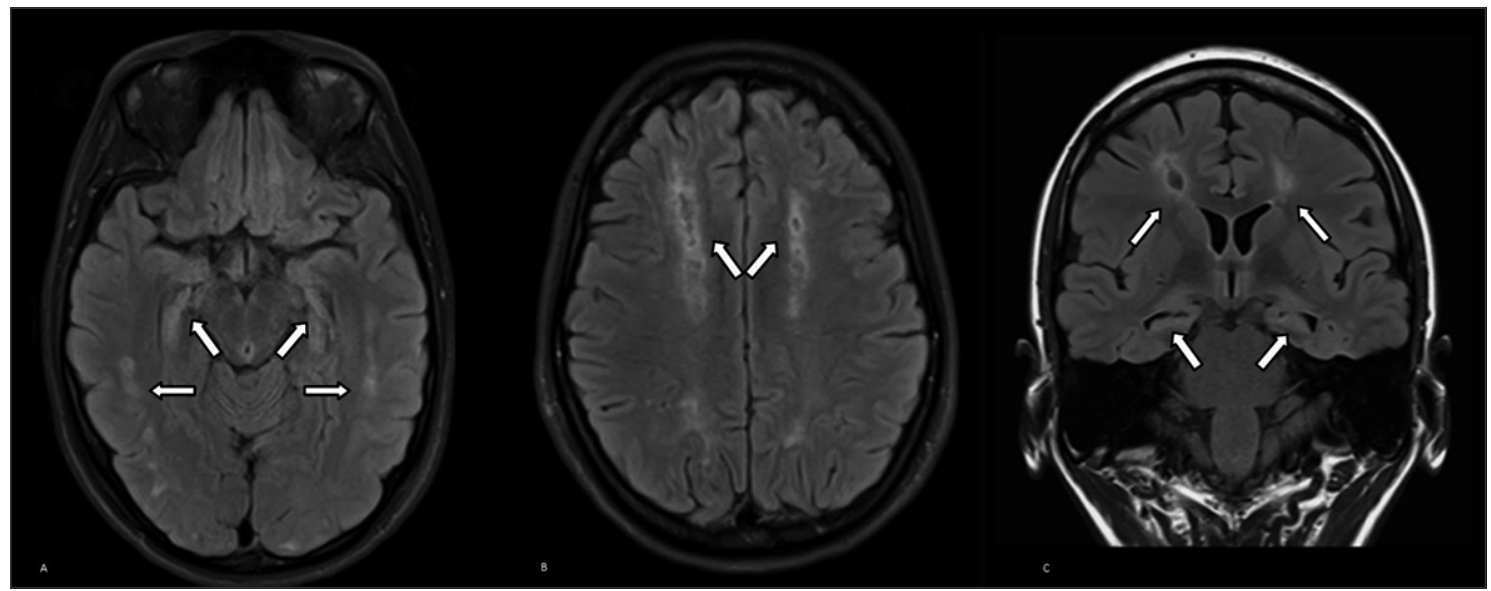

Figura 3. RM de cerebro. Imágenes obtenidas tres meses después del accidente. A) corte axial, FLAIR: Se visualiza hiperintensidad del bulbo olfatorio, atrofia hipocampal y se mantiene hiperintensidad de la sustancia blanca subcortical; B) corte axial; FLAIR: Evolución quística de las lesiones de la substancia blanca del centro semioval; C) corte coronal; FLAIR: Atrofia de ambos hipocampos, cambios quísticos de la substancia blanca frontal.

Experimentalmente se ha demostrado que la exposición al isopropanol genera compromiso de conciencia y coma en ratas que han sido expuestas a niveles de $10.000 \mathrm{ppm}$ de gases del alcohol, concentración relativamente baja, basados en la rápida recuperación de estos animales ${ }^{16}$. En la paciente la concentración del isopropanol derivado del propano no sólo alteró la conciencia, sino que dañó el SNC y originó una acidosis que permitió su diagnóstico, que fue identificada por la hiperventilación acidótica, el $\mathrm{pH}$ disminuido y la elevación del anión gap. Posiblemente debido al paso del alcohol a aldehídos y cetonas se estimuló la génesis de NADH que eventualmente pudo inhibir las enzimas intermediarias del Ciclo de Krebs, favoreciendo la producción de lactato. Felizmente, la acidosis evolucionó de manera espontánea y rápida como en cualquier intoxicación alcohóli$\mathrm{ca}$, sin haber sido plenamente comprendida en el Servicio de Urgencia.

Es interesante comentar la hipotermia de esta paciente que pudo atribuirse a su prolongada desnudez, sin embargo, se ha establecido en repetidas experiencias que la intoxicación con isopropanol produce hipotermia en los animales experimentales ${ }^{15}$ y que el isopropanol y sus derivados si bien se encuentran en todo el SNC y en el LCR en cantidades equivalente de alcoholes y acetonas ${ }^{12}$, estos alcoholes alifáticos de cadena corta tienen preferencia a ingresar al hipocampo y bulbo olfa- torio, debido a una complacencia específica de la barrera hematoencefálica ${ }^{9}$, preferencia que se puso en evidencia precozmente en los TAC realizados a la paciente (Figura 1).

En definitiva, el daño sufrido por la exposición al propano se tradujo clínicamente en una prolongada etapa de coma, inhibición del lenguaje, compromiso piramidal y deterioro cognitivo residual. Radiológicamente, en la RM se caracterizó por compromiso del centro oval con respeto de las fibras en $\mathrm{U}$ y una atrofia hipocampal y de los bulbos olfatorios. Este daño estaría relacionado con la capacidad del isopropanol para alterar la membrana basal de las neuronas ${ }^{12}$, poniendo en evidencia que la baja neurotoxicidad que se le ha supuesto al gas propano, el mayor componente del gas licuado, resulta incierta cuando la exposición al gas se prolonga. Dicha condición permite su acumulación en los tejidos y la inmediata metabolización hepática lo transforma en isopropanol que es dañino para estructuras específicas del SNC.

\section{Referencias}

1. Singh P, Lamba A, Bansal R, Singh G. Unexplained neurological events during bathing in young people: Possible association with the use of gas geysers. Ann Indian Acad. Neurol 2008 ; 11 (2): 103-5.

2. Godani M, Canavese F, Migliorini S, Sette MD. Ataxia 
with Parkinsonism and dystonia after intentional inhalation of Liquefied Petroleum Gas. Neuropsychiatric Disease and Treatment 2015; 11: 1157-9.

3. Moore AF. Final report of the safety assessment of isobutane, isopentane, n-butane, and propane. J. American College of Toxicology, 1982; 1: 127-42.

4. Bouche MP, Lambert WE, Van Bocxlaer JF, Piette MH, De Leenheer AP. Quantitative determination of n-propane, isobutane, and n-butane by headspace GC-MS, intoxications by inhalation of lighter fluid. J Analytical Toxicology 2002; 26: 35-42.

5. Aldemir E, Akyel B, Altintoprak AE, Aydin R, Coşkunol H. LPG Dependence after a Suicide Attempt. Case Reports in Psychiatry 2015; 64: 32-53.

6. Rossi R, Suadoni F, Pieroni L, Degiorgio F, Lancia M. Two cases of acute propane/butane poisoning in prison. J Forensic Sciences 2012; 57: 832-4.

7. Tsukamoto S, Chiba S, Muto T, Ishikawa T, Shimamura M. Study on the metabolism of volatile hydrocarbons in mice-Propane, n-butane and iso-butane. J Toxicol Sci 1985; 10 (4): 323-32.

8. Walker R, Flanagan RJ, Lennard MS, Mills GA, Walker V. Solid-phase microextraction: Investigation of the metabolism of substances that may be abused by Inhalation. J Chromatogr Sci 2006; 44 (7): 387-93.

9. Pardridge WM, Fierer G. Blood-brain barrier transport of butanol and water relative toN-isopropyl-p-iodoam- phetamine as the internal reference. J Cerebral Blood Flow Metabolism 1985; 5 (2): 275-81.

10. Pilegaard $\mathrm{K}$, Ladefoged $\mathrm{O}$. Toxic effects in rats of twelve weeks' dosing of 2-propanol, and neurotoxicity measured by densitometric measurements of glial fibrillary acidic protein in the dorsal hippocampus. In Vivo 1993; 7 (4): 325-30.

11. Mueller-Kronast N, Rabinstein AA, Voung L, Forteza AM. Isopropanol intoxication mimicking basilar artery thrombosis;, Neurology 2003; 61: 1456-7.

12. Rich J, Scheife RT, Katz N, Caplan LR. Isopropyl alcohol intoxication. Arch Neurol 1990; 47: 322-4.

13- Mahajan PS, Mathew JJ, Jayaram AP, Negi VC, Abu Hmaira MM. Magnetic resonance imaging features of brain and spinal cord injury in a fatal case of isopropanol intoxication. J International Medical Case Reports 2014; 7: 57-61.

14. Slaugther RJ, Mason RW, Beasley DM, Vale JA, Schep LJ. Isopropanol poisoning. Clinical Toxicology 2014; 52: 470-8.

15. Laham S, Potvin M, Schrader K, Marino I. Studies on inhalation toxicity of 2-propanol. Drug Chem Toxicol 1980; 3: 343-60.

16. Gill MW, Burleigh-Flayer HD, Strother DE, Masten LW, Mckee RH, Tyler TR, et al. Isopropanol: acute vapor inhalation neurotoxicity study in rats. J Appl Toxicol 1995; 15 (2): 77-84. 